\title{
Alveolar development after ligation of left pulmonary artery in newborn pig: clinical relevance to unilateral pulmonary artery
}

\author{
SHEILA G HAWORTH, SHEILA A MCKENZIE, MARGARET L FITZPATRICK \\ From the Department of Paediatric Cardiology, Institute of Child Health, and the Department of Medical \\ Physics, Hammersmith Hospital, London
}

\begin{abstract}
The left pulmonary artery and ductus arteriosus were ligated in 14 pigs at birth. Animals were killed at intervals between two and 24 weeks of age. In all animals, serial chest radiographs were taken. In eight animals, nitrogen-13 lung function studies showed normal fractional ventilation in both lungs and continued growth of the small left lung. After death, the fixed inflated volume was determined in each lung and alveolar development was analysed using quantitative morphometric techniques. In the right lung, after operation alveolar size increased considerably and at two weeks was similar to the normal at six months. The normal phase of rapid postnatal alveolar multiplication was delayed from the first to the second month of life. In all animals aged 20-24 weeks alveolar size was almost normal for age and an abnormal increase in alveolar number produced an abnormally large right lung. In the left lung, the alveoli multiplied to achieve a normal alveolar number in all animals sacrificed at 20 and 24 weeks, but the alveoli were abnormally small. Total lung volume was normal in all animals aged 20 and 24 weeks. The structural findings explained the radiographic and radionucleide investigations. The experimental findings are discussed in relation to lung growth in patients with an interrupted pulmonary artery.
\end{abstract}

A lung with an interrupted pulmonary artery is usually abnormally small. It is, however, well perfused at alveolar level by the bronchial arterial circulation. In patients with an interrupted pulmonary artery the mechanics of breathing and respiratory gas exchange are normal at rest and exercise. ${ }^{1-3}$ Arterial end-tidal carbon dioxide gradients are only minimally elevated, the physiological deadspace is normal, and carbon dioxide output for the lung without a central pulmonary artery is almost normal.

How both lungs develop in order to function almost normally, as they appear to do, in asymptomatic patients is not understood. The problem is of practical importance because a unilateral pulmonary artery is frequently associated with an intracardiac abnormality, and in one series $88 \%$ of such patients developed pulmonary hypertension in the contralateral lung. ${ }^{4}$ Surgically, in many cases it is now

Address for reprint requests: Dr SG Haworth, Department of Paediatric Cardiology, The Hospital for Sick Children, Great Ormond Street, London WC1N 3JH. possible to connect an interrupted pulmonary artery to the main pulmonary artery.

Previous experimental studies in which the left pulmonary artery was ligated in puppies showed that the left lung continued to increase in size with age. ${ }^{5}$ After ligation of the left pulmonary artery in newborn pigs an enlarged bronchial arterial supply to the left lung ensures almost normal development of intra-acinar arteries. ${ }^{67}$ Studying the same group of animals, this paper is concerned with alveolar development in both lungs, studied in life by performing nitrogen-13 ventilation scans and assessed after death by applying quantitative morphometric techniques to the fixed inflated lung specimen.

\section{Methods}

The Large White strain of pigs was used. The left pulmonary artery was ligated in 14 newborn animals taken from two litters. Immediately after delivery, the animals were anaesthetised and through a left lateral thoracotomy, first the ductus arteriosus and 
then the left pulmonary artery were ligated. Blood gases remained satisfactory (mean $\mathrm{pH}=7.39 \pm$ $0 \cdot 11 \mathrm{SD}$; mean $\mathrm{PCO}_{2}=40 \cdot 6 \pm 15 \cdot 8$ SD Torr), the systemic arterial oxygen tension remained above 64 Torr (mean 92.5), and the blood sugar was always greater than $50 \mathrm{mgm} / 100 \mathrm{ml}$. All animals made an uneventful recovery and were returned to the sow at between 30 minutes and six hours of age. Chest radiographs were performed daily for five days and then at weekly intervals for the first month of life. Animals were killed at intervals between two weeks and six months of age.

Nitrogen-13 lung function studies were performed in eight experimental animals, five being studied at two to four weeks and five (two animals for the second time) at seven to nine weeks of age. Two control animals were also studied twice. Having received Diazepam, $5-10 \mathrm{mg}$ by intravenous injection, each animal stood quietly underneath a Gamma camera and an end-hole catheter was placed approximately $5 \mathrm{~cm}$ inside the snout of the animal for delivery of the gas. Lung function studies were then carried out and analysed as previously described in children. ${ }^{8}$

A bolus inhalation study evaluated fractional ventilation and the lung counts at steady state measured the relative ventilated volumes of the lungs. The relative lung volumes obtained from the nitrogen-13 steady state studies were compared with the volume of the fixed inflated lung after death, using Student's paired $t$ test. Immediately before death each animal was anaesthetised and a chest radiograph and a pulmonary angiogram were taken.

\section{STRUCTURAL STUDIES}

After death, the pulmonary arterial circulation in both lungs was injected with a barium sulphategelatin mixture and the lungs inflated with fixation via the trachea. The right and left lungs were treated separately for both macroscopical and microscopical studies. When fixed, lung volume was determined by water displacement. Using a macroscopic pointcounting technique the proportion of parenchymal as opposed to other tissues within the lung was determined. ${ }^{9}$

\section{MICROSCOPIC STUDIES}

Fifteen blocks of tissue were taken at random from each lung and $4 \mu \mathrm{m}$ paraffin sections were stained with Miller's stain counterstained with van Geison's elastic stain, and with haematoxolin and eosin. All sections were examined qualitatively and analysed using morphometric techniques. The proportion of the alveolar region composed of alveolar air was determined by microscopic point-counting of randomly taken lung sections. Using an eyepiece grid, in each lung the number of alveoli per microscopic field was counted in 25 fields. In each lung total alveolar number was calculated $: 9$

$\mathbf{N}=\frac{\mathrm{n}^{\frac{3}{2}}}{\beta \sqrt{\rho}} \times \mathbf{P} \times \mathbf{V}$,

where $\mathbf{N}=$ total alveolar number

$\mathrm{n}=$ number of alveoli per unit area

$\beta=$ alveolar shape constant of 1.55

$\rho=$ proportion of alveolar air

$\mathbf{P}=$ proportion of parenchymal lung tissue

$\mathrm{V}=$ lung volume

The number of alveoli per $\mathrm{ml}$ of parenchyma was calculated in order to compare the size of alveoli in different lungs.

\section{Results}

\section{CHEST RADIOGRAPHS}

The right lung was abnormally translucent with a flattened right hemidiaphragm in all animals on the first day after operation and during the first six to eight weeks of life. At all ages the right lung was larger than the left and after 16-20 weeks appeared larger than the right lung of age-matched controls. The left lung was small in all animals but it increased in size with age. On the first day after operation and for the first eight to 16 weeks of life, the left lung appeared hypertranslucent. In animals killed at 20 and 24 weeks the left lung periphery was hypertranslucent but lung markings were visible in the hilar and mid-zone regions. "Bronchial wall thickening" was seen in the left lower lobe in radiographs of all animals the day after operation, and became more prominent in all animals with age. A small area of lung immediately beneath the thoracotomy site was poorly aerated at all ages.

\section{NITROGEN-13 VENTILATION SCANS}

In each animal the rate of clearance of nitrogen-13 (fractional ventilation) was the same in both lungs, was similar in all eight animals, and did not differ from that in the two controls. For the group of experimental animals, the mean ratio of the nitrogen13 ventilated volume of the right lung to that of the left was $2.18 \pm 0.33(\mathrm{SD})$, as compared with $1.2 \pm$ 0.001 (SD) for a group of normal pigs of the same age $(p<0.001)$. The mean ratio of the ventilated volume of right and left lung in the group of experimental animals studied at two to four weeks did not differ significantly from that of the group studied at seven to nine weeks of age.

POST-MORTEM LUNG VOLUME

At two weeks the volume of the right lung was 
Table 1 Right lung. Volume, alveoli per $\mathrm{ml}$, alveolar number

\begin{tabular}{|c|c|c|c|c|c|}
\hline Pig no & Age (weeks) & Volume $(\mathrm{ml})$ & $V o l / k g(m l / k g)$ & Alveoli per $\mathrm{ml} \times 10^{6}$. & Total alveolar number $\times 10^{6}$ \\
\hline 1 & 2 & 75 & $22 \cdot 1$ & $1 \cdot 8$ & 138 \\
\hline 2 & 2 & 84 & $16 \cdot 8$ & $1 \cdot 5$ & 189 \\
\hline 3 & 4 & 80 & 19 & $2 \cdot 4$ & 195 \\
\hline 4 & 4 & 115 & $22 \cdot 5$ & $1 \cdot 7$ & 201 \\
\hline 5 & 8 & 315 & $18 \cdot 3$ & $2 \cdot 1$ & 654 \\
\hline 6 & 8 & 230 & 20 & $2 \cdot 4$ & 556 \\
\hline 7 & 8 & 370 & $16 \cdot 7$ & $2 \cdot 0$ & 737 \\
\hline 8 & 16 & 535 & $13 \cdot 4$ & $1 \cdot 8$ & 951 \\
\hline 9 & 16 & 730 & $15 \cdot 5$ & $1 \cdot 9$ & 1351 \\
\hline 10 & 20 & 920 & $15 \cdot 5$ & 1.8 & 1686 \\
\hline 11 & 20 & 1160 & $13 \cdot 3$ & $1 \cdot 4$ & 1639 \\
\hline 12 & 24 & 1380 & $17 \cdot 8$ & $1 \cdot 6$ & 2208 \\
\hline 13 & 24 & 1500 & $18 \cdot 2$ & $1 \cdot 7$ & 2504 \\
\hline 14 & 24 & 1135 & $14 \cdot 2$ & $1 \cdot 5$ & 1730 \\
\hline \multirow[t]{8}{*}{ Normal values } & 1 day & 58 & - & $4 \cdot 36$ & 233 \\
\hline & 1 week & 74 & $43 \cdot 5$ & $4 \cdot 18$ & 255 \\
\hline & 2, & 101 & $38 \cdot 8$ & $3 \cdot 69$ & 325 \\
\hline & 4 , & 160 & $29 \cdot 6$ & $3 \cdot 56$ & 482 \\
\hline & $8 \quad$, & 288 & 13 & $2 \cdot 66$ & 550 \\
\hline & 12, & 451 & 14.9 & $2 \cdot 65$ & 970 \\
\hline & 16, & 597 & 14 & $2 \cdot 57$ & 1090 \\
\hline & 24 & 1128 & $13 \cdot 2$ & $1 \cdot 46$ & 1460 \\
\hline
\end{tabular}

Table 2 Left lung. Volume, alveoli per ml, alveolar number

\begin{tabular}{|c|c|c|c|c|}
\hline Pig no & $\begin{array}{l}\text { Age } \\
\text { (weeks) }\end{array}$ & $\begin{array}{l}\text { Volume } \\
(\mathrm{ml})\end{array}$ & $\begin{array}{l}\text { Alveoli } \\
\text { per } \mathrm{ml} \times 10^{6}\end{array}$ & $\begin{array}{l}\text { Total alveolar } \\
\text { number } \times 10^{6}\end{array}$ \\
\hline 1 & 2 & 40 & $3 \cdot 45$ & 138 \\
\hline 2 & 2 & 45 & $4 \cdot 07$ & 183 \\
\hline 3 & 4 & 35 & $5 \cdot 25$ & 184 \\
\hline 4 & 4 & 50 & $5 \cdot 06$ & 253 \\
\hline 5 & 8 & 135 & $2 \cdot 04$ & 276 \\
\hline 6 & 8 & 140 & 3.98 & 557 \\
\hline 7 & 8 & 170 & $2 \cdot 9$ & 405 \\
\hline 8 & 16 & 340 & - & - \\
\hline 9 & 16 & 350 & - & - \\
\hline 10 & 20 & 480 & $2 \cdot 28$ & 1098 \\
\hline 11 & 20 & 640 & $1 \cdot 83$ & 1168 \\
\hline 12 & 24 & 500 & $1 \cdot 86$ & 931 \\
\hline 13 & 24 & 610 & $2 \cdot 12$ & 1291 \\
\hline 14 & 24 & 710 & $1 \cdot 7$ & 1245 \\
\hline \multirow[t]{8}{*}{ Normal values } & 1 day & 48 & $4 \cdot 36$ & 190 \\
\hline & 1 week & $60 \cdot 3$ & $4 \cdot 18$ & 208 \\
\hline & 2 & 82 & 3.69 & 265 \\
\hline & 4 & 131 & $3 \cdot 56$ & 394 \\
\hline & 8, & 236 & $2 \cdot 66$ & 450 \\
\hline & 12 & 369 & $2 \cdot 65$ & 792 \\
\hline & 16 & 488 & $2 \cdot 57$ & 890 \\
\hline & 24 & 923 & 1.46 & 1195 \\
\hline
\end{tabular}

reduced. This was true for both absolute volume and mean lung volume relative to body weight (table 1). Subsequently right lung volume increased with age and was larger than normal in five of the seven animals killed at 16-24 weeks, and normal in the remaining two animals. The volume of the left lung increased with age but was less than normal for age in all animals killed at two to 24 weeks (table 2). The volume of the left lung was approximately 53.3-54\% that of the right, at two weeks, increased to a maximum of $60 \cdot 9-78 \cdot 5 \%$ at eight weeks, but by 24 weeks was only $36 \cdot 2-62 \cdot 6 \%$ of the right lung volume.
Thus, in animals aged 2 and 4 weeks total lung volume was below normal for age. In older animals, because of the abnormal increase in volume of the right lung, total lung volume was within normal limits by 20-24 weeks of age.

For the group, the mean ratio of the volume of the right lung to that of the left obtained postmortem was not significantly different from that obtained in life with nitrogen-13, using Student's paired $t$ test.

\section{MICROSCOPIC FINDINGS}

Right lung Histologically, the alveoli in all animals appeared mature and normal. Point-counting indicated a normal volume proportion of alveolar air to alveolar duct air with respect to age.

Left lung In all animals the subcostal region of the upper lobe showed areas of collapse, fibrosis, and an increase in elastic tissue of the alveolar walls. In the remainder of the lung the alveoli were small but structurally they appeared normal. In all animals, point-counting demonstrated an increase in the proportion of alveolar duct air relative to the proportion of alveolar air.

NUMBER OF ALVEOLI PER CC

Right lung The number of alveoli per $\mathrm{ml}$ was below normal for age in all animals killed at 2-16 weeks of age, indicating abnormally large alveoli (table 1). Animals killed at eight weeks generally had a greater number of alveoli per $\mathrm{ml}$ than did the younger animals, indicating a rapid phase of multiplication occurring about four weeks later than is seen in the normal lung. ${ }^{10}$ At $20-24$ weeks the number of alveoli per $\mathrm{ml}$ was normal or slightly elevated (fig). 


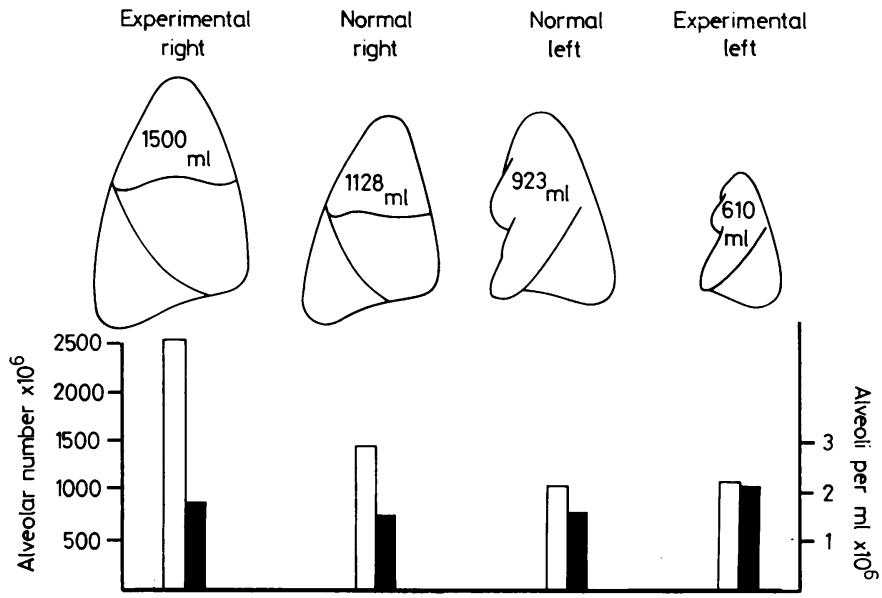

Figure Lung volume, alveolar number $(\square)$ and alveoli per $\mathrm{ml}(\square)$ in the lungs of experimental pig 13, aged 24 weeks, compared with normal. In the right lung of the experimental animal, lung volume and alveolar number are increased and alveoli per $\mathrm{ml}$ is normal. In the left lung, volume is reduced, alveolar number is normal, and the increase in alveoli per $m l$ indicates $a$ reduction in alveolar size.

Left lung The number of alveoli per cc increased between 2 and 4 weeks of age, indicating a rapid phase of alveolar multiplication (table 2). There was a reduction in the number of alveoli per cc between 4 and 24 weeks of age, as is normal. In all animals, however, the left lung contained more alveoli per cc than is normal for age, indicating that although the alveoli were growing they remained abnormally small.

\section{TOTAL ALVEOLAR NUMBER}

In both the right and left lungs at two weeks total alveolar number was reduced for age and the number of alveoli was similar to that in the normal animal at 6-12 hours of life suggesting failure of alveolar multiplication (tables 1, 2).

Right lung Total alveolar number was increased in several older animals and in all those killed at 20 and 24 weeks of age. At 24 weeks, alveolar number was $118-171 \%$ of the normal value (fig).

Left lung Alveolar number increased with time but was below normal for age in the majority of animals killed during the first eight weeks of life.

Alveolar number at 20 and 24 weeks was within normal limits in four of the five animals studied and just below normal in the remaining animal.

Total alveolar number of both lungs The total

Table 3 Summary of results, $2 \rightarrow 24$ weeks

\begin{tabular}{llc}
\hline & Right lung & Left lung \\
\hline Lung volume & $\downarrow \rightarrow \mathbf{N} \rightarrow \uparrow$ & $\downarrow \rightarrow \downarrow \downarrow$ \\
Alveolar size & $\uparrow \rightarrow \downarrow \rightarrow \mathbf{N}$ & $\downarrow \downarrow \rightarrow \downarrow$ \\
Total alveolar number & $\downarrow \rightarrow \uparrow \rightarrow \uparrow$ & $\downarrow \rightarrow \mathbf{N} / \downarrow$ \\
\hline
\end{tabular}

Vertical arrows indicate comparison with normal

Horizontal arrows indicate change with time between 2 and 24 weeks. number of alveoli in both lungs therefore was below normal for age in all animals killed during the first four weeks and was normal or increased in all older animals. An increased number of alveoli in both lungs was not due to these experimental animals being unusually large for age. The results are summarised in table 3 .

\section{Discussion}

In the chest radiographs, the hypertranslucent emphysematous appearance of the right lung immediately after operation was shown to be caused by an increase in alveolar size. Thus the radiological and pathological features of pulmonary overdistension co-existed. By contrast, the hypertranslucent appearance of the left lung was caused by a reduction in blood flow, and a rapid reduction in size of lobar and segmental pulmonary arteries. Thus in the left lung the radiological appearance suggestive of overdistension did not correspond with the pathological findings, indeed the alveoli were abnormally small, but was the result of an increase in proportion of air relative to blood within the lung. The peribronchial shadowing was caused by enlargement of the bronchial arterial circulation which provided the only source of blood supply to the lung. ${ }^{6}$

In the left lung, at necropsy there was no evidence of airways disease and in life fractional ventilation was normal using nitrogen-13. The nitrogen-13 ventilated volume of the left lung was small, but increased with age, and as a proportion of total ventilated lung volume, did not change significantly with age. These in vivo measurements are explained by the continued multiplication of alveoli after two to four weeks with some increase in alveolar size. 
Considering the animals as a group, there was no significant difference between the in vivo and postmortem measurements of relative lung volume, suggesting that most of the left lung was ventilated in life.

After operation, in the right lung the alveoli increased in size so rapidly that by two weeks, alveolar size was similar to that in the normal at 6 months of age. However, the phase of rapid alveolar multiplication was delayed after operation until between four and eight weeks rather than occurring during the first four weeks as is normal. ${ }^{10}$ At 2 weeks of age the severity of the reduction in alveolar multiplication was indicated by the lung volume being smaller than normal despite an increase in alveolar size.

In animals sacrificed at 20 and 24 weeks of age an abnormally large right lung was composed of additional alveoli of normal size. These findings are very similar to those in the contralateral lung after unilateral pneumonectomy in laboratory animals. ${ }^{11}$ Pneumonectomy causes an increase in both weight and volume of the remaining lung. ${ }^{12-14}$ These changes are accompanied by an increase in DNA and protein content as well as in stable RNA/DNA ratio, suggesting cellular hyperplasia rather than hypertrophy. ${ }^{12} 15$

Quantitative morphometric techniques have not previously been used to study alveolar development after ligation of a pulmonary artery at birth. The findings in the present study are, however, similar to those described by Langston et al ${ }^{11}$ who applied similar morphometric techniques to study the effect of a left pneumonectomy in 10-week-old rabbits. Four weeks after surgery, they reported a $60 \%$ increase in alveolar number in the right lung, giving an alveolar number similar to that in both lungs of the control animals. Alveolar size was normal. Also, as in the present study, there was no significant increase in the size of the alveolar ducts to account for the increase in lung volume.

Reports on the effect of pneumonectomy on alveolar number in different species are conflicting. The present study emphasises the necessity of studying a series of animals killed at varying time intervals after surgery, and also of first establishing the normal pattern of alveolar development in that species.

After ligation of the left pulmonary artery, in the left lung the alveoli multiplied to achieve a normal or near normal alveolar number by about 20 weeks of age. Thus, bronchial blood flow ensured relatively normal development of the acinus, as it did of the intra-acinar arteries, ${ }^{7}$ but the alveoli did not increase in size normally with age. The pathophysiological mechanism responsible for growth failure is not understood. Recently, the same pattern of alveolar development was found in the lungs of a baby who died at 3 months of age with a severe stenosis of the right pulmonary artery and an enlarged bronchial arterial circulation to that lung. ${ }^{16}$ Similarly, small alveoli were also found in the right lung of a child is in whom accidental surgical occlusion of the right $\vec{\circ}$ pulmonary artery had occurred in infancy. ${ }^{17}$

\section{CLINICAL IMPLICATIONS}

In the growing lung, experimental occlusion of one pulmonary artery has been shown to affect the growth and development of both lungs. Since in the human infant alveolar multiplication occurs mainly during the first three years of life, ${ }^{18}$ it is obviously preferable to correct the vascular abnormality in infancy. Alveoli continue to increase in size, however, until adolescence and since in the pig, deprivation of the blood supply reduced alveolar size rather than number, restoration of pulmonary artery continuity in childhood would probably allow the lung to grow normally. Fletcher et $a^{17}$ reported $\vec{\oplus}$ an increase in lung volume after restoration of $\stackrel{\infty}{\rightarrow}$ pulmonary arterial continuity in a child with pulmonary arterial occlusion acquired at 9 weeks of age. They attributed the increase in lung volume to alveolar dilatation because of the rapidity of the response. It is also encouraging that in all the $\stackrel{\circ}{\mathbb{D}}$ experimental animals fractional ventilation was normal in the small lung.

Radionuclide regional lung function studies help distinguish between a poorly perfused hyperlucent lung with normal ventilatory function and a hyperlucent lung with obliterative bronchiolitis. ${ }^{19}$ In the present series the nitrogen-13 lung function studies reflected the structural findings in the lungs. Quantitative radionuclide lung function studies may help monitor the growth and development of the lung in children with a unilateral pulmonary artery, and indeed in any child with a hypoplastic lung. They should also help to evaluate the effect of reconstructive surgery connecting an interrupted $\frac{7}{2}$ pulmonary artery to the right ventricle, by serial determinations of the relative volume of the affected $\stackrel{N}{\circ}$ lung.

We thank Mr P Buckingham and other members of the staff of the Medical Research Council Cyclotron Unit for providing and dispensing the nitrogen-13. \& We would like to acknowledge financial support by the National Fund for Research into Crippling 0 Diseases (SAMcK) and by the Joint Research Board $\vec{\Phi}$ of the Hospitals for Sick Children and the Institute of Child Health. 


\section{References}

${ }^{1}$ Ferguson A, Belleau R, Gaensler EA. Congenital absence of one pulmonary artery. Respiration 1969;26:300-12.

${ }^{2}$ Madoff IM, Gaensler EA, Strieder JW. Congenital absence of right pulmonary artery. $N$ Engl J Med 1952;247: 149-57.

${ }^{3}$ Tabakin BS, Hanson HS, Adhikari PK, Miller DB. Physiologic studies in congenital absence of left main pulmonary artery. Circulation 1960;22:1107-11.

4 Pool PE, Vogel JHK, Blount SG Jr. Congenital unilateral absence of a pulmonary artery. The importance of flow in pulmonary hypertension. Am J Cardiol 1962;10:70632.

${ }^{5}$ Liebow AA, Harrison W, Hales MR. Experimental pulmonic stenosis. Bull Int Assoc Med Museums 1950; No 31:1-23.

${ }^{6}$ Haworth SG, de Leval M, Macartney FJ. How the lung is perfused after ligating the left pulmonary artery in the pig at birth. Cardiovasc Res 1981;15:214-26.

${ }^{7}$ Haworth SG, de Leval M, Macartney FJ. Hypo- and hyperperfusion in the immature lung: pulmonary arterial development following ligation of left pulmonary artery in the newborn pig. J Thorac Cardiovase Surg $1981 ; 82: 281-92$.

${ }^{8}$ Ronchetti R, Stocks J, Freedman N, Glass H, Godfrey S. Clinical application of regional lung function studies in infants and small children using 13N. Arch Dis Child 1975;50:595-603.

9 Dunnill MS. Quantitative methods in the study of pulmonary pathology. Thorax $1962 ; 17: 320-8$.

${ }^{10}$ Haworth SG, Hislop AA. Adaptation of the pulmonary circulation to extra-uterine life in the pig and its relevance to the human infant. Cardiovasc Res 1981;15: 108-19.

${ }^{11}$ Langston C, Sachdeva P, Cowan MJ, Haines J, Crystal RG, Thurlbeck WM. Alveolar multiplication in the contralateral lung after unilateral pneumonectomy in the rabbit. Am Rev Respir Dis 1977;115:7-13.

12 Buhain WJ, Brody JS. Compensatory growth of the lung following pneumonectomy. J Appl Physiol 1973;35:898902.

${ }^{13}$ Nattie EE, Wiley CW, Bartlett D Jr. Adaptive growth of the lung following pneumonectomy in rats. $J$ Appl Physiol 1974;37:491-5.

14 Tartter PI, Goss R-J. Compensatory pulmonary hypertrophy after incapacitation of one lung in the rat. $J$ Thorac Cardiovasc Surg 1973;66:147-52.

${ }^{15}$ Cowan MJ, Crystal RG. Lung growth after unilateral pneumonectomy: quantitation of collagen synthesis and content. Am Rev Respir Dis 1975;111:267-77.

${ }^{16}$ Haworth SG, Silove E. Pulmonary arterial structure in pulmonary atresia following $\mathrm{PGE}_{2}$ administration. $\mathrm{Br}$ Heart J 1981;45:311-6.

${ }^{17}$ Fletcher BD, Garcia EJ, Colenda C, Borkat G. Reduced lung volume associated with acquired pulmonary artery obstruction in children. Am J Roentgenol 1979;133:4752.

${ }^{18}$ Davies G, Reid L. Growth of the alveoli and pulmonary arteries in childhood. Thorax 1970;25:669-81.

19 McKenzie SD, Allison DJ, Singh MP, Godfrey S. Unilateral hyperlucent lung-the case for investigation. Thorax 1980;35:745-50. 